\title{
Enhancing Architectural Representations in 3D Virtual Reality: Building Denotative and Connotative Meanings
}

\author{
Üç Boyutlu Sanal Gerçeklik Ortamında Mimari Mekan Temsilinin Geliştirilmesi: \\ Temel Anlam ve Yan Anlam Yaratma
}

\author{
Erdal Devrim AYDIN, 남 Togan TONG
}

Virtual reality, since being a new form of architectural representation; when compared to traditional forms of representations, is a medium of representation which the narrative techniques are still in the process of developing. In traditional forms of representation, the viewer is actively directed in both the navigation and view, while in the architectural representations in the virtual reality medium, the viewer who now becomes the user, is left to her/his own personal decisions. Hence, the examples produced in the field of virtual reality are less successful in conveying spatial narratives than in traditional types of representation. In this study, a method has been proposed to develop the representation possibilities of the virtual reality environment by using the denotative and connotative meaning creation techniques of cinema. In the proposed method, meaning creation techniques of the cinema were used together with the interaction element of virtual reality, which is its most unique facility. By using the lighting technique between the denotative and connotative meaning creation methods of the cinema dynamically in the virtual reality medium according to the user interaction, introducing a spatial narrative to the user is directed. The discovery of the narrative possibilities of the virtual reality environment will enable it to be used more effectively as an architectural representation and moreover it will ensure this medium to be accepted as a new genre of art production.

Keywords: Architectural representation; computer aided architecture; computer aided design; representation; spatial perception; virtual reality.

ÖZ

Sanal gerçeklik, yeni bir mimari temsil biçimi olması nedeniyle, geleneksel temsil biçimlerine göre, anlatım teknikleri henüz gelişmekte olan bir temsil ortamıdır. Geleneksel temsil biçimlerinde izleyici hem gezinti hem de bakış olarak etkin biçimde yönlendirilirken, sanal gerçeklik ortamındaki mimari temsillerde, kullanıcı haline gelen izleyici, tamamen kendi kişisel tercihlerine bırakılmaktadır. Bu nedenle sanal gerçeklik alanında üretilen örnekler, mekansal anlatıyı aktarmada geleneksel temsil biçimlerine göre daha az başarılı olmaktadır. Bu çalışmada sinemanın temel anlam ve yan anlam üretme teknikleri kullanılarak sanal gerçeklik ortamının temsil olanaklarının geliştirilmesi için bir yöntem önerilmiştir. Önerilen yöntemde, sinemanın anlam üretme teknikleri ile, sanal gerçekliğin özgün olanağı olan etkileşim öğesi birlikte kullanılmıştır. Sinemanın temel anlam ve yan anlam üretme yöntemleri arasındaki ışıklandırma tekniği, sanal gerçeklik ortamında kullanıcı etkileşimine göre dinamik olarak kullanılarak, kullanıcıya bir mekansal anlatı aktarmak amaçlanmıştır. Sanal gerçeklik ortamının kendi anlatım olanaklarının keşfedilmesi, mimari temsil olarak daha etkin kullanılmasını hatta bu ortamların yeni bir sanat üretim alanı olarak kabul edilmesini sağlayacaktır.

Anahtar sözcükler: Mimari temsil; bilgisayar ortamında mimarlık; bilgisayar ortamında tasarım; temsil; mekansal algı; sanal gerçeklik.

Department of Architecture, Yıldız Technical University Faculty of Architecture, İstanbul, Turkey

Article arrival date: December 17, 2018 - Accepted for publication: April 05, 2019

Correspondence: Erdal Devrim AYDIN. e-mail: mimerd@gmail.com

○ 2019 Yıldız Teknik Üniversitesi Mimarlık Fakültesi - @ 2019 Yıldız Technical University, Faculty of Architecture 


\section{Introduction}

The discipline of architecture, which uses traditional forms of representation, such as drawings, perspectives, photographs and video imagery, is introduced to new discussion areas in terms of both the ability of the computer to mimic these representations and to provide new opportunities for representation. The power of digital representation that affects not only the space but also the way we perceive and define the whole world, changes the representation of the architectural space.

As a result of the increase in their capacities, computer systems have begun to enable creating three-dimensional virtual reality environments. With the aid of a displaying device, virtual reality environments give architects much more opportunities to present the spaces they create. Thus, virtual reality, has become a medium of architectural representation.

In the practice of architecture, the place of representation has much more importance than the other branches of art. Especially because of cost and scale hindrances, architects are obligated to use many representational mediums together or separately, to present their design to the audience. While artists such as painters, writers, photographers and graphic designers can present a preliminary study of their works in their own respective fields of art without the need for another medium of representation; architects on the other hand, in order to explain their work, need other forms of representations.

Representational mediums used by the architects are original production mediums of other arts. Artists such as painters, photographers, musicians, writers or cinematographers use their own representational mediums to convey thoughts and feelings to their audiences. For this purpose, they have to direct the audience according to the narrative, in the representational medium they use. In literature, the author introduces and injects elements that will support the story, in music the composer gives priority to the sounds and harmonies that will strengthen the main theme and in photography and cinema (even in painting and in sculpture) the view of the spectator is directed according to the narration.

However, none of these traditional representations is a mechanical reproduction of reality and as a matter of fact, these representations all have constraints. More importantly, as Rudolf Arnheim points out, these constraints of a representational medium are necessary elements to strengthen the expression of the artist. ${ }^{1}$ The artist, who wants to direct the audience according to a narration, uses both the possi-

Arnheim, 2002: 55-56. bilities and the constraints of the medium. ${ }^{2}$ For instance, the frame, which is a constraint for the mechanical reproduction of reality, becomes a tool for directing the gaze of the spectator in painting, photography and cinema.

Hence, architects must know the possibilities and constraints of the representation medium they use when trying to arrive at a narrative about the their work and use them as a means of expression.

The virtual reality medium, on the other hand, has the potential to become indistinguishable from the physical reality, with the developing of technology. Consequently, the constraints used by other representational mediums as a means of expression are no longer valid for the virtual reality. As Saakes and Stappers have pointed out, this situation leads to the perception of the virtual reality medium as a raw repetition of phsyical reality, not as a medium of representation. However, this perception also causes the story telling potential of virtual reality to be overlooked. ${ }^{3}$ As a result, the architectural space modeled on a computer is directly presented in the virtual reality medium for navigation of the user. In other architectural representations, while architects use the possibilities and constraints of the representation medium, in virtual reality, a narrative cannot be reached because they can't direct the participants in these environments...

However, accurate descriptions of the unique narration possibilities of the virtual reality medium, even including their constraints, will provide an understanding of the methods of use as a form of architectural representation as well. Just as in the beginning of the 20th century, trying to understand the possibilities of the cinema, which was a new form of representation and trying to find ways to use these opportunities effectively as a means of expression, the 3D virtual reality medium also requires such an effort. In fact, this effort will enable the virtual reality environment to be defined not only as an architectural representation tool, but also as a new art field. ${ }^{4}$

Brenda Laurel underlined the need to take "catharsis theorem" from theater as an example in computer-human

\footnotetext{
In his book on the cinema as a form of art, Arnheim sets up a silent movie scene. "Imagine a person in a forest with a gun he points to the other person who lifts the revolver.", says Arnheim, "Then, with an image cut, an image of trees shot from a distance enters the scene and all of a sudden, all the birds take off. From this scene, we learn that the weapon exploded with a big bang. However, if it was a sound movie, the director would not have to resort to such an artistic expression. Therefore, the limitation of the medium, thus paves the way for the artistic expression." Arnheim, 2002: 94. Arnheim builds on the determinations about the artistic power of perspective again on the "limitedness of the medium" discourse. "...However, if there is no impression of depth, the perspective is remarkable and impressive. What appears, what is hidden, draws attention only when they are arranged for the intended purpose; the person is forced to think to understand why the objects are arranged in this way rather than in other ways eye..." Arnheim, 2002: 55-56.

3 Saakes and Stappers, 2001: 1-2.

4 Virtual reality film festivals are clear indicators that this medium is began to be accepted as a field of artistic production.
} 
interaction. ${ }^{5}$ According to the theatrical form set forth by Aristotle in his work "Poetics", Saakes and Stappers, which had taken the "catharsis" theorem, ${ }^{6}$ as the basis of their study in $\mathrm{CAVE}^{7}$ environment, users are taken into a virtual reality environment with a transition between the real world and the virtual world. Thus, a perceptual split between virtual reality and the real world is avoided and identification is ensured. In a study of two different groups of architecture students, users found this virtual reality experience more satisfying. In the study conducted by Nitsche et al. in 2003, it has been propounded that the alienation effect created by the computer monitor created a cinematographic narrative possibility for the virtual reality. In the virtual reality environment created in this study, users are enabled to trigger a dramatic action when they reach certain points during their stroll in the space and are made to follow or participate in this dramatic action without their own will. As a result, Nitsche and other researchers have emphasized the importance of dramatic action in the user's experience of the space and argued that virtual reality spaces "without meaning" are not effective with regards to the user. ${ }^{8}$ In a study conducted by Burtnyk and other researchers upon the introduction of a car model, users can move according to their navigation choices around the car on the circular planes at a fixed distance, when they come to the edge of these planes, they start watching a video introducing the car outside beyond their will. At the end of the video, the users find themselves on another navigable plane and at the end of that plane another video plane is placed. Burtnyk and other researchers, therefore, interrupted the user's own navigation choices by showing the views that they wanted to show according to their narration. ${ }^{9}$

The common point in these studies is that users are exposed to situations or actions other than their own will. In the representation environment, the viewer must be directed in accordance to the narration, but in the virtual reality environment, the viewer transforms into the user. The main reason for this is the fact that the concept of interaction, which is barely or not found in other forms of representation, is the main element of virtual reality. Thus, while experience in other mediums takes place in one-way direction (from representation to viewer), the virtual reality medium allows two-way interaction by allowing user's will. In these studies, the original expression possibilities of traditional representation mediums have been used, with-

\footnotetext{
Laurel, 1991: 18-19.

6 According to "catharsis tehorem" of Aristotle, audience members put themselves into the shoes of the character on the stage and feel the same emotions as the actor. Aristoteles, 1999: 22, 37

Room in which images are projected its three or more walls with

projections. The 3-D images projected on the walls according to the perspective of the user entering the room, enable the user to fee themselves to be in the virtual reality environment defined by these images.

Nitsche et al. 2003: 297

Burtnyk et al. 2003: 101-102.
}

out taking interaction element's unique opportunity of the virtual reality into account. While a medium is used to convey a narrative, possibilities from other mediums can be borrowed. However, medium of representation provides the power of expression from its original narration esentially. Although it is a visual and aural art, cinema's original expression elements are movement and time, which are used in the medium of film more effective than in any other mediums.

The power of the cinema, which is also called the "art of montage", is due to its ability to manage time in this way. ${ }^{10}$ Hence, interaction is the own unique expression possibility of the virtual reality.

In this study, it is aimed to reach a narrative by using the interaction element which is the most significant difference of the virtual reality. If interaction in these virtual worlds is orientated correctly, it has the potential to turn into a narration tool. The virtual reality applications made by orientating these preferences without limiting the spatial interaction and navigational preferences of the user, but according to the narrative intended to be transmitted, the potential of the virtual reality environment shall be seen.

An architectural representation primarily intends to create a spatial perception in its viewer (or its user). When different theorems developed on spatial perception are examined, it is seen that they have a consensus on the concept of "the cognitive map". According to Montello, ${ }^{11}$ a cognitive map which is the intrinsic representation of the information and spatial characteristics of the world stored in memory, it also involves the processes of acquisition, representation and processing of this information, according to Evans. ${ }^{12}$ Furthermore, both Evans and Montello underline that cognitive maps do not resemble the cartographic maps that we know. Although Evans and Montello do not give a full view on the reason for this, Mendoza states that cognitive maps don't include only visual information, but also include non-spatial elements such as bitterness, drought and toxicity as well. ${ }^{13}$

In his book "The Image of the City", Kevin Lynch outlines elements that human beings used to describe a city are paths, nodes, landmarks, districts and edges. It can be also said that he also presents elements which form cognitive maps. ${ }^{14}$

If the space is presented to the audience from a representational medium, the movement of the viewer and the cognitive map he/she creates together with this circulation are controlled according to the thought or emotion that is intended to be conveyed about the space. So the

\footnotetext{
${ }^{0}$ Arnheim, 2002: 78-79.

11 Montello, 1997: 1.

${ }^{12}$ Evans, 1980: 261-262
}

${ }^{13}$ Mendoza, 2010: 2, 7

${ }^{14}$ Lynch, 1990: 46-48. 


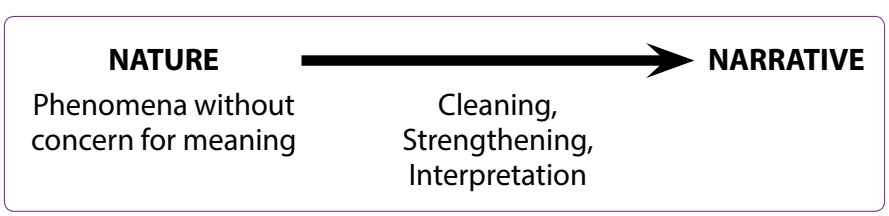

Figure 1. Diagram showing narrative production process in representation environments according to Herbert Zettl.

\begin{tabular}{|c|c|c|}
\hline ARCHITECTURE & & SPATIAL NARRATIVE \\
\hline $\begin{array}{l}\text { Places whose } \\
\text { purpose is to } \\
\text { provide shelter } \\
\text { which also have } \\
\text { concern for meaning }\end{array}$ & $\begin{array}{l}\text { Cleaning, } \\
\text { Strengthening, } \\
\text { Interpretation }\end{array}$ & $\begin{array}{l}\text { Meaning of space } \\
\text { Habitability of space } \\
\text { Physical properties of the } \\
\text { space, etc. }\end{array}$ \\
\hline
\end{tabular}

Figure 2. The formation of spatial narrative in architectural representation.

elements which are mentioned by Lynch are emphasized on the representational medium. For example, in cinema, a certain course of navigation is observed and elements such as reference points of this route, regions, roads, etc., are displayed with preferences of framing, color, clarity, etc., geared towards the narrative. In summary, the spatial perception of the viewer is guided in accordance with the spatial narrative.

Herbert Zettl states that in order to direct the perception of the human and to convey a narrative in a medium of representation, the phenomena provided by nature and which do not bear concern for the meaning, need to go through the processes of cleaning, strengthening and interpretation ${ }^{15}$ (Fig. 1). The artist who wants to convey the narrative, tries to direct the audience's senses to a certain and cleaned phenomenon by limiting their free or uncontrolled selectivity in the natural environment. In other words, the phenomena that was not intended to be perceived are cleansed and the phenomena intended to be perceived are strengthened.

In architectural representation, the medium used for artistic production is used to reach the spatial narrative. If the relationship established by Zettl has to be re-established in terms of architectural space, the process seen in Figure 2 is reached. Among many features of the space designed consciously, the features that are intended to be explained are strengthened and other features are cleared because they do not serve the narrative. When creating space perception, the free will of the viewer is eliminated, and he/she is directed to a cognitive map which is suitable for the spatial narration.

In the virtual reality environment, the process must be same to reach the spatial narrative. Since virtual reality is basically a visual and auditory medium of representation, it will be appropriate to base on / focus attention on the

\footnotetext{
${ }^{15}$ Zettl, 1999: 4.
}

methods of similar mediums. Painting, photography and film are available mediums of representation that virtual reality can take example of. However, since it includes the elements of film, sound, time and movement, it has a wider range of narrative methods for virtual reality than painting and photography.

James Monaco, in his work entitled "How to Read a Movie?", examines how the film (or even the visual arts) produces meaning as a medium of representation. Here, Monaco argues that an image has two meaning dimensions:

- Denotative Meaning

- Connotative Meaning ${ }^{16}$

According to Monaco, when an image of a rose is seen in a film (or other visual arts), this image of the rose itself is first and foremost a "denotative". This dimension is the basic semantic dimension. However, the way in which a rose is shown (in vivid or faint colors, above or below the frame, from a bottom or top shot, etc.) includes the narrative that is intended to be conveyed with the image of the rose. This in fact, is the connotative meaning. According to Monaco, it is indispensable process to build a connotative meaning, if a medium of representation is used for conveying a thought or a feeling. This connotative meaning creation in cinema takes place in two ways:

- Paradigmatic Connotative Meaning: Connotative meaning obtained by the in-frame arrangements of the image. Frame arrangements such as the position of the display in the frame, color preferences, light preferences, etc., help to build this connotative meaning. All visual arts use these connotative meaning creation techniques.

- Syntagmatic Connotative Meaning: It is the connotative meaning obtained by moving images according to the position of an image in the sequence of other images or showing them fast, slow, backward, etc. Syntagmatic connotative meaning creation techniques are specific to the art of cinema because it consists of moving images. In performing arts, such as theater, syntagmatic connotative meaning creation techniques are also used. ${ }^{17}$

When the virtual reality medium is evaluated through connotative meaning creation techniques of the film medium, the problems of virtual reality examples which the user is not directed also arises. In a virtual reality environment, when the user is not directed to convey a spatial narrative, the medium only shows its basic denotative meaning. The space is left to the user's own free perception. Thus, the representation medium is not used in accordance with its purpose. However, the virtual reality becomes a medium of representation if both the possibilities

\footnotetext{
${ }^{16}$ Monaco, 2005: 157-158. $\quad{ }^{17}$ Monaco, 2005: 158-159.
} 
of the film medium and the possibility of interaction which is a unique ability for virtual reality are used to convey the connotative meaning.

In our study, it is aimed to reach a connotative meaning conveyance method that includes spatial narrative in the medium of virtual reality. For this purpose, a space has been selected and a feature of this space has been defined as a connotative meaning. Afterwards, with a narration method using the interaction element, an attempt was made to convey this connotative meaning to experiment participants. In order to evaluate the results, an experimental and a control group was formed separately. In the control group's virtual reality environment, the methods for creating a spatial narration which were used in the experiment group's environment, weren't used to test the method's success.

In the method used in the study, in accordance with the chosen spatial narrative, first and foremost the navigation route and view of the user is aimed to be guided. Thus, the user is tried to be provided to come up with a cognitive map in accordance with connotative meaning. After this has been achieved, the connotative meaning was tried to be conveyed with visual interventions in accordance with the spatial narrative. Thus, by guiding the user's navigation route, the syntagmatic connotative meaning and by converting the image present on where the user looks, paradigmatic connotative meaning was attempted to be conveyed. However, unlike previous studies, it has not been preferred to restrict and direct the user outside his/ her own will. Limiting and redirecting the user outside his/ her own will implies the elimination of the interaction feature. Therefore, the aim of this study is to reach a spatial narrative without damaging the element of interaction, which is the unique possibility of virtual reality.

In order to test the method, virtual reality environment must have some special characteristics. First of all, the venue should include navigation alternatives. A space with a unidirectional linear circulation area, without offering route alternatives, is insufficient to test the method's success. In addition, the space should not only consist of walls. A space consisting of galleries, vertical circulation alternatives, spaces with openings and independent elements separated from walls has the potential to offer different perspectives to the user.

In order to provide these spatial features, METU ${ }^{18}$ Faculty of Architecture Building was chosen as the place to be transferred to the virtual reality environment. The METU Faculty of Architecture has many features that can be selected for spatial narrative with its continuous circulation area suitable for large and multi-purpose use, galleries increasing the richness of the space, inner courtyards, dif-

\footnotetext{
${ }^{18}$ Middle East Technical University, Ankara, Turkey
}

ferent flooring layers at various levels and the use of natural light. The METU Faculty of Architecture, designed by Behruz Çinici and Altuğ Çinici, who won the competition in 1961 for the METU Campus in Ankara, was put into service in 1963 [URL-1].

The experiment participants were selected from Yıldız Technical University Department of Architecture sophomore students. Because of the architectural knowledge of the participants and a method in the proposal stage, the use of natural light, which is a simple and easy to understand feature of METU Faculty of Architecture building, has been chosen. In the structure, while the natural light is used in the lighting of the circulation area, it has been observed that special attention was paid: Natural light is positioned to illuminate the stairs in the circulation area. Although it is possible to say that the natural lighting seen in Figure 5 is an element generally used in buildings, it is also possible to say that this choice is made consciously in Figure 3 , when the holes in the upper level are opened and in the Figure 4, where the light gaps in the ceiling are taken into consideration (Figs. 3-5).

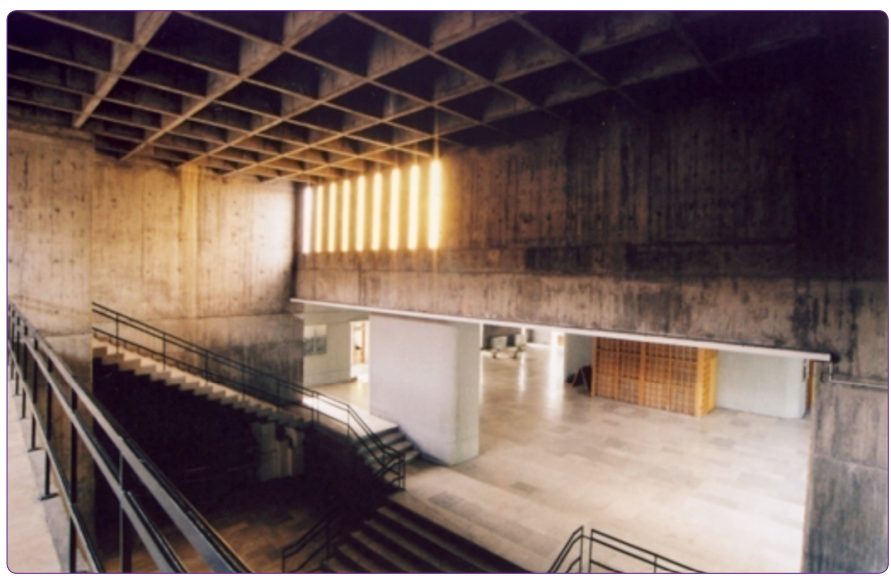

Figure 3. METU Faculty of Architecture, natural lighting - staircases relationship.

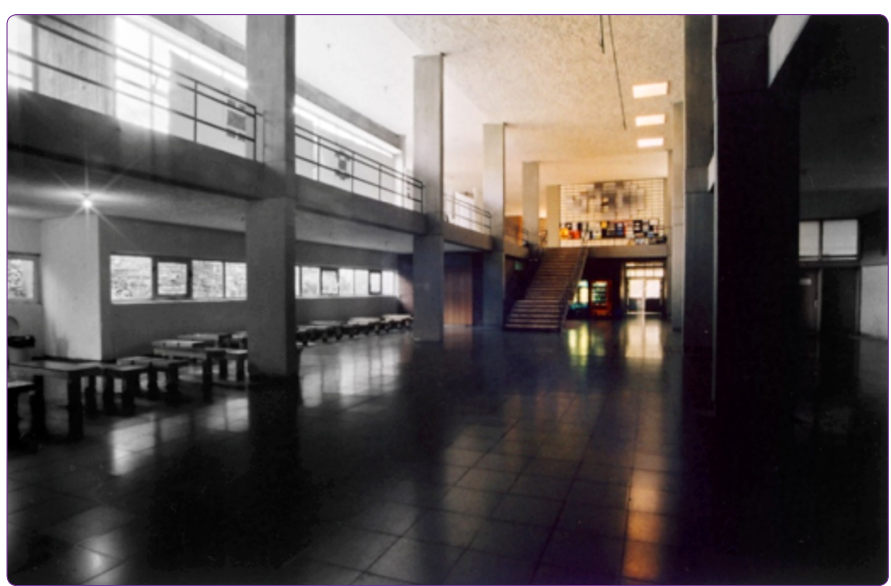

Figure 4. METU Faculty of Architecture, natural lighting - staircases relationship. 


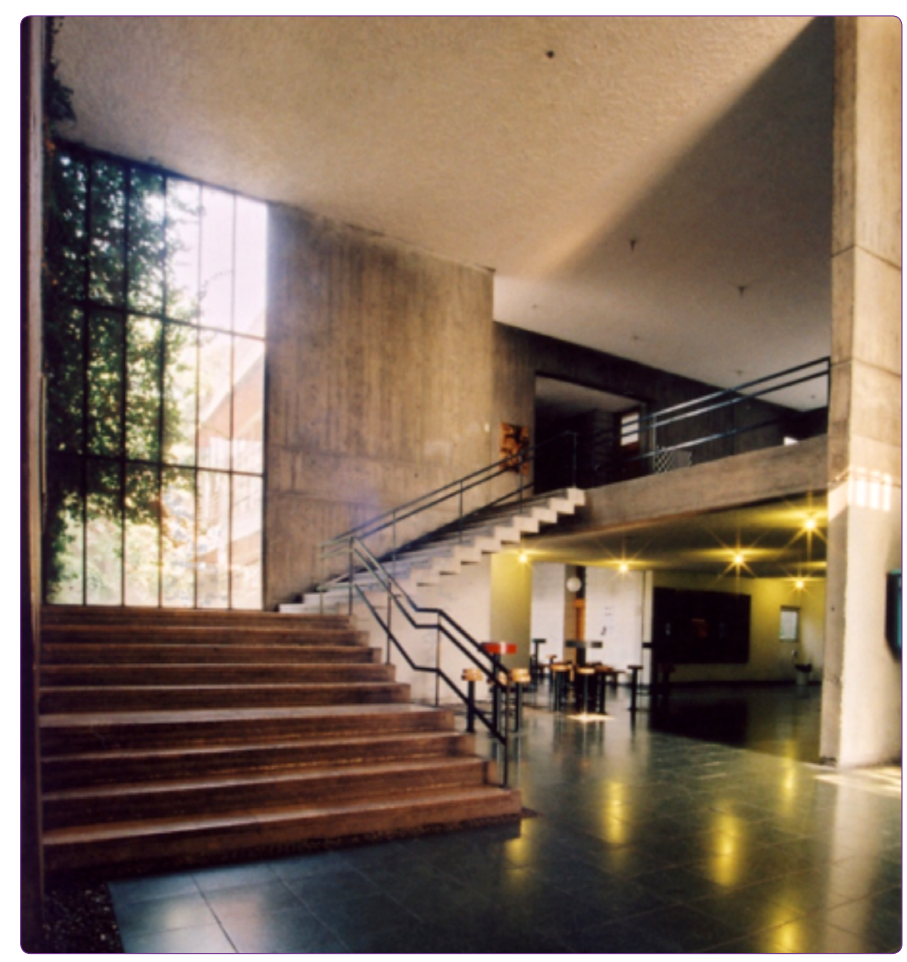

Figure 5. METU Faculty of Architecture, natural lighting - staircases relationship.

Since the spatial feature that is intended to be conveyed to the experimental group is a choice of lighting, the lighting technique in a virtual reality environment is preferred to be used. Visual arts, due to their nature, intensively use lighting methods as narrative technique. For the purpose of guiding the experimental group and conveying the narrative, the chiaroscuro lighting technique intensively used in the cinema was chosen. Chiaroscuro lighting technique in cinema is inspired by the techniques of Renaissance painters such as Rembrandt and Caravaggio. In chiaroscuro lighting, the lights are positioned to direct the viewer's attention to the objects or people that are intended to be shown. At the same time, by creating a dramatic effect, this lighting helps to convey emotions and expression. In addition, regions or objects that do not serve the narrative in the space are left in the dark to strengthen the narrative. In the experimental group as well, paradigmatic connotative meaning was sought to be produced by using chiaroscuro lighting to show the relationship between natural lighting and stairs. ${ }^{19}$

In order not to restrict the user's direction preferences, but to allow them directing to a certain route, in the structure, five points indicating this kind of natural lighting feature are illuminated in a certain order. At the same time, the virtual space is illuminated for the purpose of orientation according to the position of the user in order to monitor this sequence. When the user reached a certain

\footnotetext{
${ }^{19}$ For further information about Chiaroscuro Lighing, Zettl, 1999: 35-39.
}

point, the point intended to be shown was illuminated, the lighting was switched off once the user was directed to that particular point and dynamic lighting was created by illuminating the next point in the sequence. The goal is to ensure that the user, from the moment he/she starts walking in the virtual space, to stay on a certain navigation path with the help of dynamic lighting and to create a syntagmatic connotative meaning to perceive the specified feature of that particular location. The switching on and off of the lighting is not done suddenly; both actions are graded with equal tempos such that the user is unaware of the transition. In this way, it is aimed to eliminate the effect of artificiality in the user's experience at the venue.

Figure 6 shows the plan of the circulation area of the building. From the starting point, the orientation points are shown with letter $D$ and the points of natural lighting are shown with the letter $L$.

The virtual space produced in the Control Group is modeled with fully homogeneous lighting, which is frequently performed in virtual reality environments.

In the preparation of the model; AutoCAD software was used in technical drawings, ArchiCAD and 3DS Max software were used in modeling. Quest 3D 4.2.2 software was used to transfer the model to a virtual reality environment.

The navigation in the prepared virtual reality environment was made from the computer screen and participants moved with the help of the arrow keys on the keyboard. Before the experiment, the participants were taken to a simple VR environment so that they would get used to this navigation method. A limited time of 3 minutes is provided for the test environment. Thus, it is ensured that the question of whether the duration of the navigation was sufficient or not was also among the questions.

In order to understand whether or not the participants in the experimental group formed the predetermined cognitive map and to understand whether or not they apprehend the connotative meaning, both the experimental and the control groups were asked one written question, six rating scale questions and one sketch drawing. The navigations of all participants were recorded on camera, as well.

In the written question, it was requested to evaluate the adequacy of the navigation time. Since the navigation route of the control group is not guided, it is predicted that the participants of the control group shall find the navigation time more insufficient than those in the experimental group.

In the Rating scale questions, participants were asked to grade the lighting of the place, the complexity of the circulation system, the levels of the flooring elevations and the sense of reality. In this grading, participants were asked to agree or disagree by giving a grade ranging from 1 to 5 to 


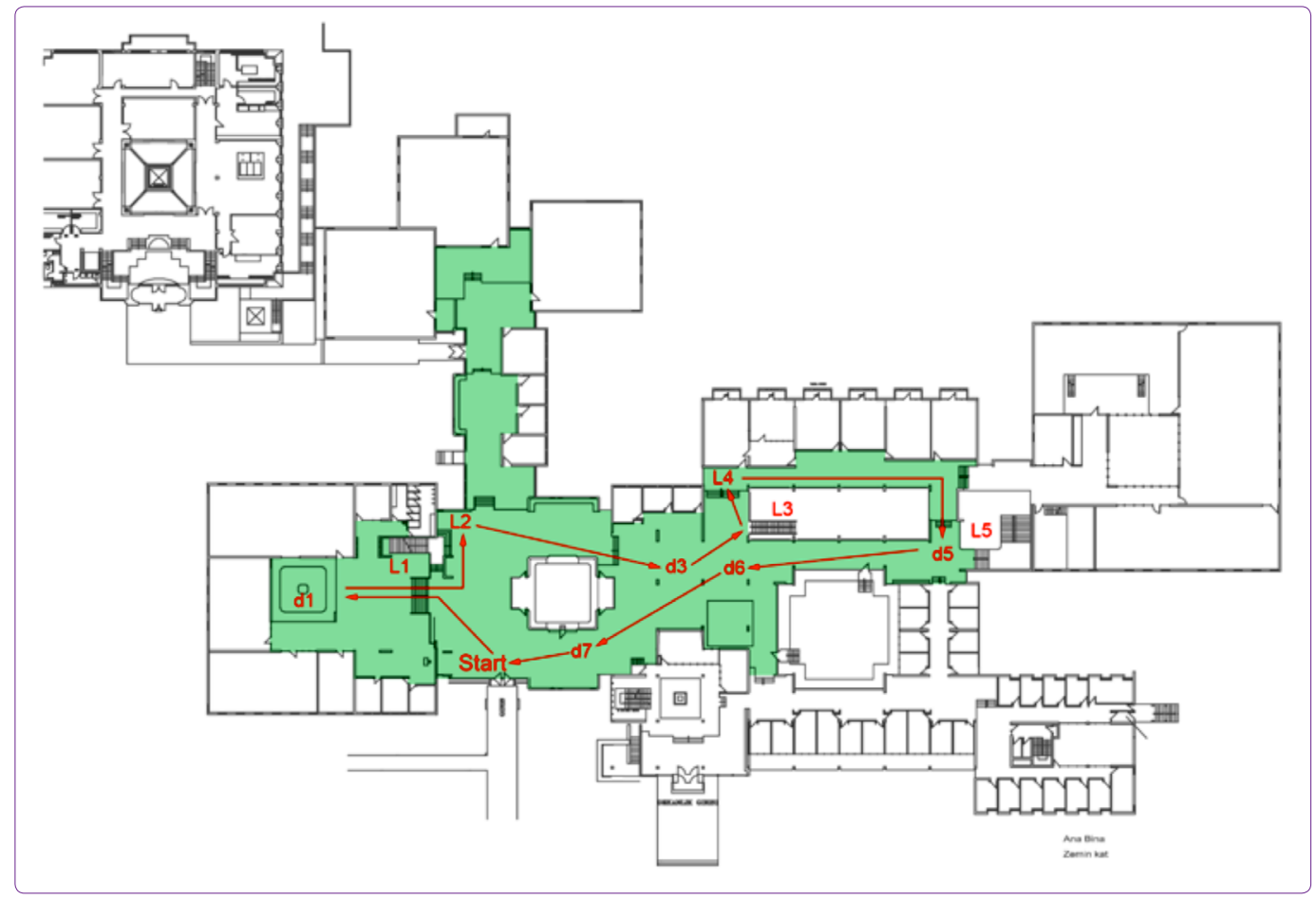

Figure 6. Route selected for the experiment group.

in the statements given. In order to determine the average score, the Disagree option is equalized to the score of -2 and Agree option to the score of +2 . The 3 -point value on the other hand, was accepted as 0 and it was determined as undecided. Then, by taking the weighted average of these grades of the participants, the tendency of the group to agree in general was revealed.

In case of the sketch drawing question, the participants were given the plan of the place they navigated and were asked to draw the missing stairs. Here again it was predicted that the participants in the experimental group will be able to place the missing stairs more accurately than of those in the control group.

14 students of architecture have participated both at the control and experimental groups each.

According to the responses of the participants, 1 participant from the experimental group and 4 from the control group found the experiment time insufficient. Participants who found the time insufficient in the control group, stated that "They could not navigate consciously because they did not know what to pay attention to." They also said that they found the circulation system in the venue to be complex. As a matter of fact, when the navigation routes were examined, it was observed that the wanderings of the control group users spread over a wider area. In the homogeneously illuminated environment, Control Group participants perceived the space more widely and followed a scattered navigation route because there was no orientation (Figs. 7 and 8). As a result, the control group participants found the time to be less sufficient than the experimental group participants.

As seen in Figure 9, 2 participants from the experimental group said that elevations of the floor levels did not attract their attention. In the control group, the agreement rate to this proposition was 1.57 and in the experimental group, it was close to undecided. Since the participants in the experimental group were directed to a connotative meaning related to illumination, it was observed that they did not pay attention to other features in the space.

The control group participants agreed with 1.21 points over the experimental group with 0.57 points for the proposition about the natural lighting (Fig. 10). This is because homogeneous and high-intensity lighting use in the control group environment and darker lighting use in the experimental group environment. It is observed that a well-lighting and getting natural light is considered as similar. Hence, the fact that the control group did not agree with the proposition that the space has insufficient light to a large extent and the experimental group remaining undecided, proves this (Fig. 11). When viewed together with the graphic in Figure 11, it is seen that the Control Group participants have the idea that the space is naturally light and that the lighting is sufficient due to the fact that the environment is brighter.

Against the proposition stating, "Attention was paid for the staircases in the space to receive natural lighting" which was chosen as the connotative meaning that was tried to be conveyed in the study, 3 persons among the Control Group participants have checked "It didn't attract 


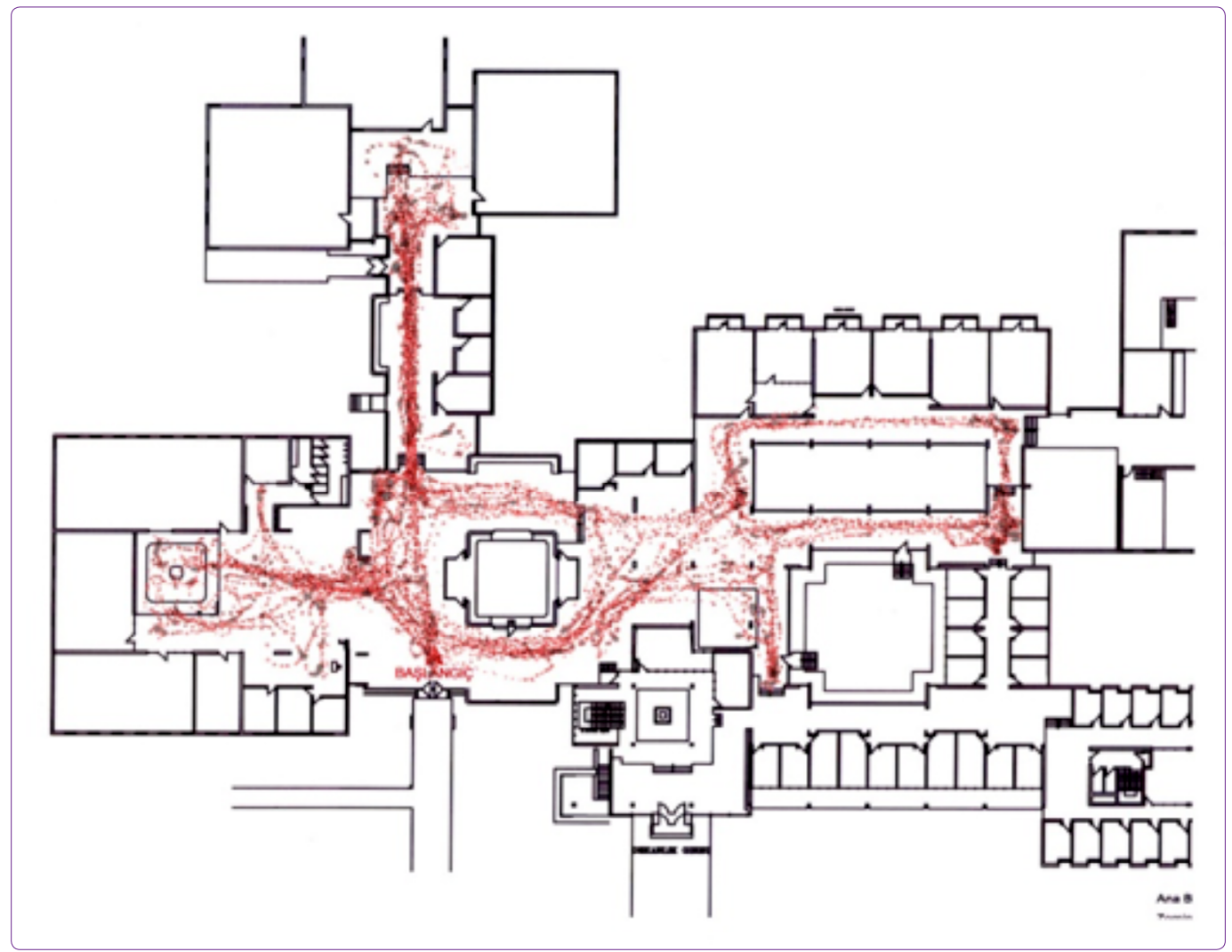

Figure 7. Navigation traces of the Control Group users.

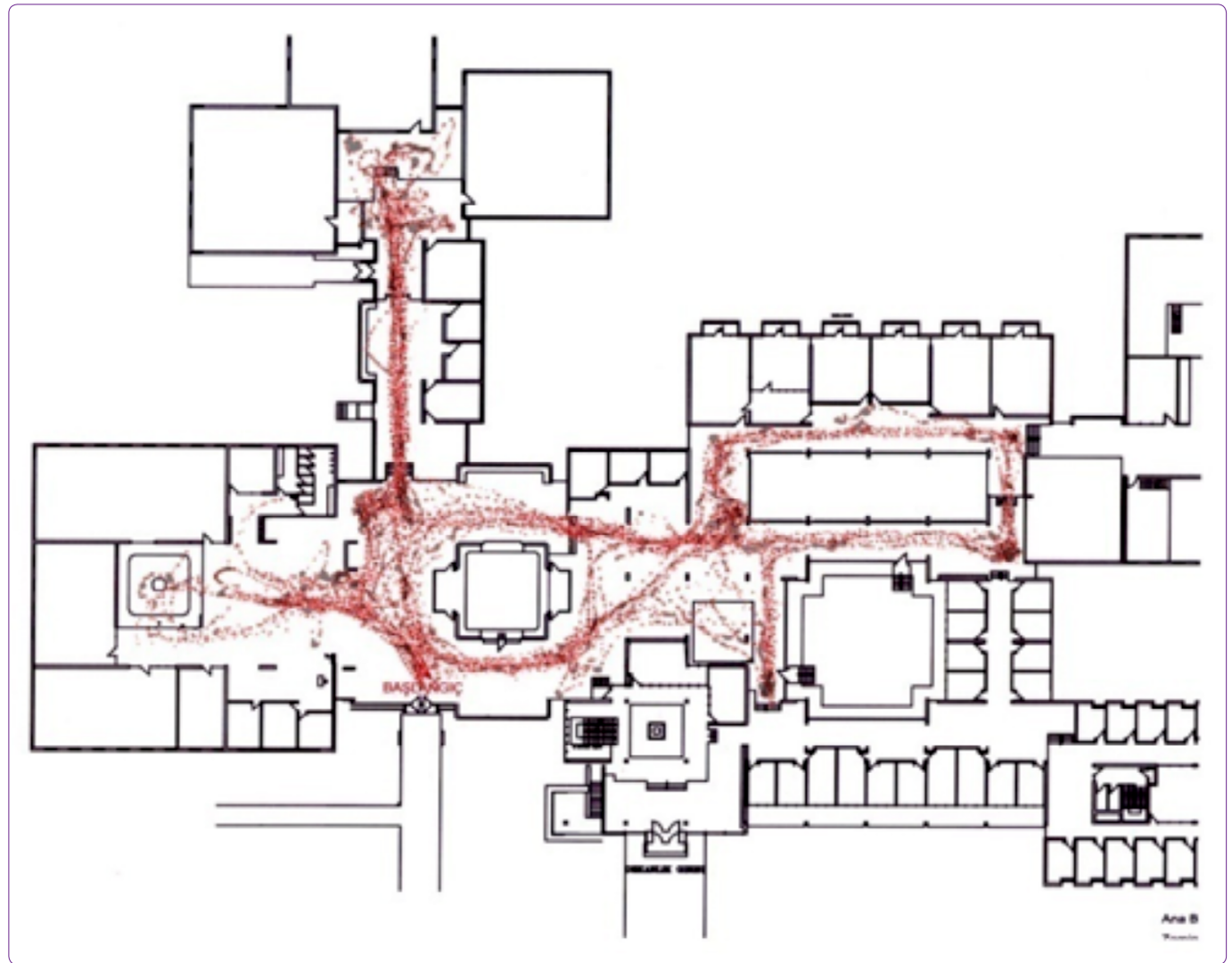

Figure 8. Navigation traces of the Experimental Group users. 


\section{Floor levels were placed at various elevations}

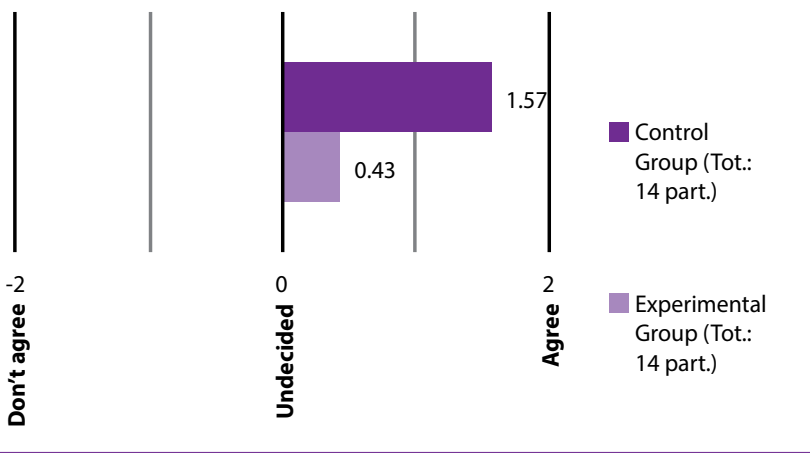

Figure 9. Scores given to the proposition about flooring levels.

\section{Natural lighting is considered in design}

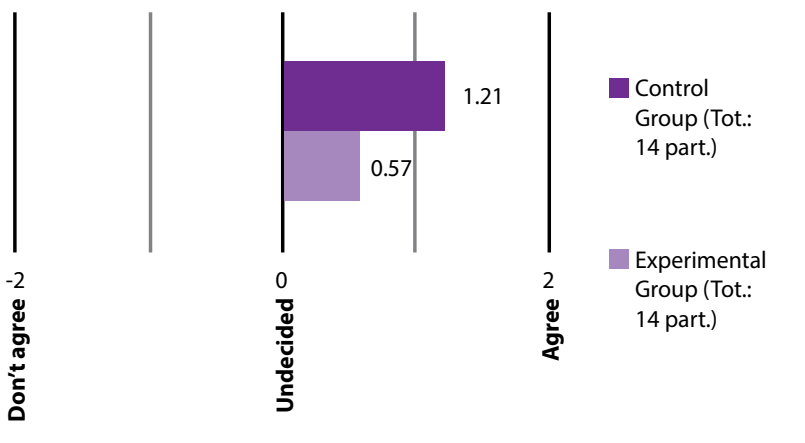

Figure10. Scores given to the proposition about the natural lighting

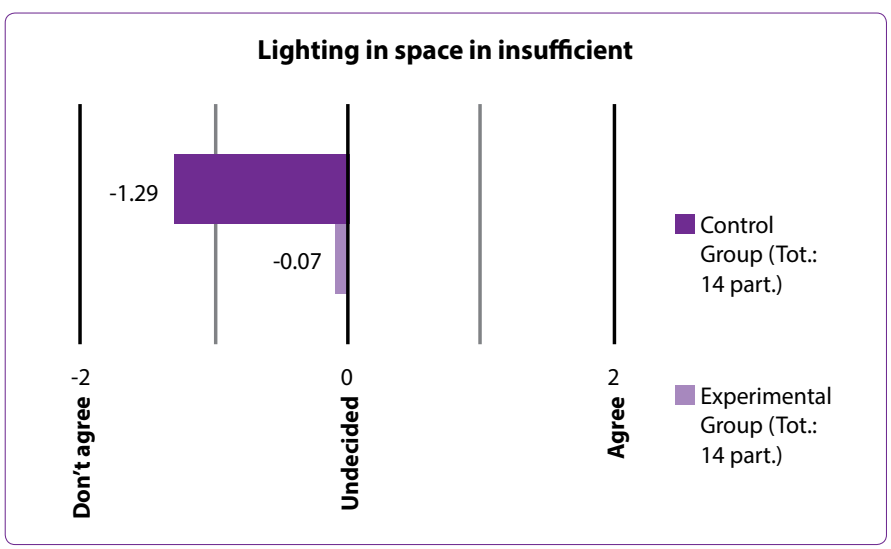

Figure 11. Agreement rate to the proposition about the insufficiency of lighting in the space.

my attention" option. In the Experiment Group, no users have checked this option.

When agree-disagree rates for the proposition is examined, a low level of disagreement is seen in the control group. The experimental group participants remained undecided. The fact that all participants in the experimental group paid attention to this feature showed that the guidance to the connotative meaning desired to be conveyed was successful. This is confirmed by the fact that there are

\section{Attention was paid for the staircases in the} space to reveive natural lighting

$\mid$
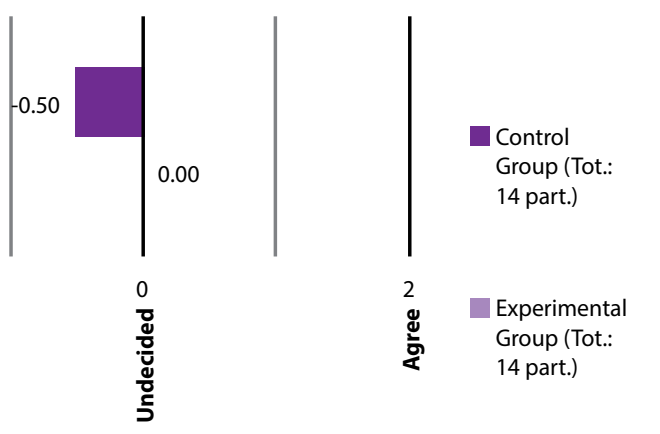

Figure 12. Scores given to the proposition regarding the stairs in the space receiving natural lighting.

The circulation system of the space is complex
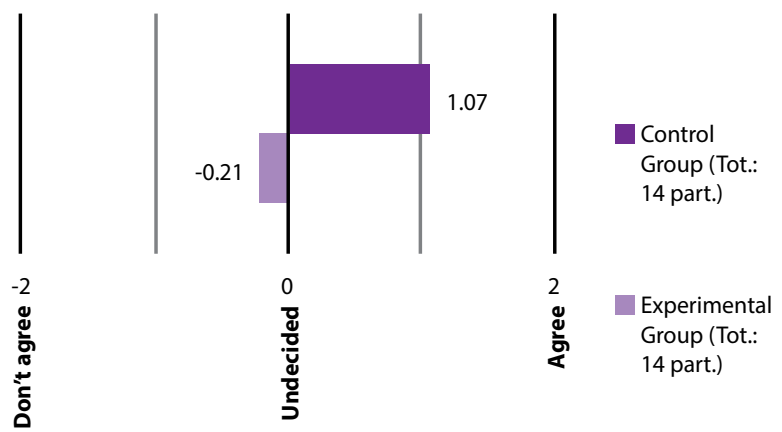

Figure 13. Grades given to the proposition about the circulation system of the space.

3 people who do not pay attention to this feature within the control group. The level of agreement in the proposition shows that the application of the experiment should be improved (Fig. 12). Also, due to problems ${ }^{20}$ caused by the inadequacy of Quest 3D software, the fact that some of the lighting techniques have not been fully utilized has led to these results.

In the evaluation of the circulation system of the space, it was seen that control group participants found the circulation system more complicated than the experimental group (Fig. 13).

\footnotetext{
${ }^{20}$ Due to the high number of objects in the model, some objects have been observed as lost in the virtual reality environment obtained from Quest 3D software. In addition, it is determined that different objects are lost in every run of EXE file where the virtual reality environment is present and no warning is given about this problem. In order to obtain a photo-realistic image in the 3D Studio MAX environment, the number and size of the coating materials prepared by the "Texture Baking" process increased these problems. Due to the disappearance of some objects in the last taken output model, this technique which is vital for the experiment was abandoned and it was decided to use the light sources which can be integrated within Quest 3D software. A lighting system with high-quality light texture and shading could not be implemented due to the fact that the light sources integrated into the Quest 3D software have a more primitive lighting system than the 3D Studio MAX software and, more importantly, cannot create shadow.
} 
Since the control group environment has homogeneous illumination without any guiding, it is seen that the participants of this group perceive the circulation system as complex. However, the dynamic illumination technique used enabled the cognitive maps of the experimental group participants to be much clearer.

Both groups were undecided with similar values to the proposition that the sense of reality in the space was strong.

In the sketch drawing section where the participants were asked to position the stairs, only 4 participants from the control group and 8 from the experimental group drew the sketches. As this number is insufficient compared to the total group, it is difficult to make an evaluation, although, a total of 2 staircases from the control group and 6 staircases from the experimental group were positioned accurately. This shows that the participants of the experimental group, though albeit a few, paid attention to the staircases compared to those participants of the control group.

From the answers given to the propositions, it is seen that the users in the Experimental Group remain largely loyal to the cognitive map sought to be conveyed. Particularly, it was observed that the paradigmatic connotative meaning was successful in Experimental Group users and they paid more attention to whether the staircase elements in the space received natural lighting or not.

However, when looking at the camera records, it is not possible to say that the dynamic lighting system aiming to direct the navigation path that creates the syntagmatic connotative meaning has achieved the same success. Users in the Experiment Group did not comply with the lights which were lit in sequence according to their navigation routes.

Despite the fact that dynamic lighting for the purpose of routing did not reach its goal, the responses of the users are similar to the predictions also proves that the user's cognitive map does not resemble cartographic maps. Therefore, although the user did not follow the recommended route exactly, she/he was able to approach the desired cognitive map with the help of the dynamic lighting which created the paradigmatic connotative meaning. The fact that users in the Experimental Group follow a less scattered route than the Control Group, even if they did not follow the route, show that the dynamic lighting method has the potential to convey the syntagmatic connotative meaning of a space.

The cognitive measurements carried out on the virtual reality environments created for the Control and Experimental Groups indicate that the dynamic lighting interventions made to improve the representation of the architectural space are instruments of high potential which are special for virtual reality environments. It is possible to accept the virtual reality environment as a space of representation and to transform the cognitive map of a user into an environmental narrative rather than using homogeneous illumination. Nevertheless, as we have mentioned previously, dynamic lighting alone does not suffice as a narrative instrument. In addition to the development of dynamic lighting technique, the use of other representational mediums in collaboration with such technique will also improve the unique representation capabilities of virtual reality environments. However, the point to take into consideration is that the "interaction" concept should be paid attention to as it distinguishes virtual reality among other representational environments.

In the experiment carried out for the study, the users experienced the virtual reality environments using a keyboard, mouse and a screen. Interaction devices such as virtual glasses and data gloves, etc. are among the variations that distinguish these environments from other representational mediums. The type of interaction established between the user and the environment also affects the production and control of the cognitive map that pertains to such an environment. Virtual glasses technologies have witnessed significant developments since 2012 when the study was performed. Virtual glasses such as HTC Vive and Oculus Rift have now introduced this technology into our daily lives. These glasses eliminate the concept of pragmatic connotative meaning as they do not offer a frame such as a screen. Instead, spatial connotative meaning applies for the question which is an area of interest of the architecture. Therefore, it is clear that the virtual reality environments created in this study achieve distinctive results if experienced by users with virtual reality glasses.

In order to develop spatial representations of virtual reality as a field of visual representation, it is necessary to take advantage of the techniques of prior visual representation forms. Apart from dynamic lighting, which uses the "interaction" element, the most important feature that distinguishes virtual reality from other representation mediums, the use of visual expression techniques such as color, depth of field and the expression techniques developed for other interaction tools will ensure that these environments have distinctive semantics and language. When virtual reality is discovered in its original narrative possibilities, it will be used much more effectively as a medium of architectural representation. Hence, this change will not only affect the field of architectural representation but will also makes virtual reality a branch of art with its own unique tools.

\section{References}

Aristoteles (1999) "Poetika”, Çev: İsmail Tunalı, Remzi Kitabevi, 8. Basım, ìstanbul. 
Arnheim, R. (2002) "Sanat Olarak Sinema", Türkçesi: Rabia Ünal, Öteki Yayınevi, Ankara.

Burtnyk, N., Khan, A., Fitzmaurice, G., Balakrishnan, R. and Kurtenbach, G. (2002) "StyleCam: Interactive Stylized 3D Navigation using Integrated Spatial \& Temporal Controls", Proceedings of the ACM Symposium on User Interface Software \& Technology, ACM Press, New York, pp. 101-110.

Evans, G. W. (1980) "Environmental Cognition", Psychological Bulletin. 88, pp. 259-287.

Laurel, B. (1991) "Computers as Theatre”, Addison-Wesley Publishing Co., Reading.

Lynch, K. (1990) The Image of the City, The MIT Press, Cambridge, 20th Printime, Massachusetts.

Mendoza, A. C. and Del Castillo, N. (2010), "The meaning of the meaning of houses: An interdisciplinary study", 44th Annual Conference of the Architectural Science Association, ANZAScA 2010, Unitec Institute of Technology http://anzasca.net/2010-conference-papers/ [Erişim Tarihi: 8.12.2018].

Monaco, J. (2005) "Bir Film Nasıl Okunur?", Çev: Ertan Yılmaz, Oğlak Bilimsel Kitaplar / Sinema, Oğlak Yayınları, 6. Baskı, İstanbul.
Montello, D. (1997) "Unit006 - Human Cognition of the Spatial World", NCGIA Core Curriculum in GIS, http://www.geo. upm.es/postgrado/CarlosLopez/materiales/cursos/www. ncgia.ucsb.edu/giscc/units/u006/u006.html, [Erişim Tarihi: 8.12.2018].

Nitsche M., Roudavski, S., Penz, F. and Thomas, M. (2003), "Drama and Context in Real-Time Virtual Environments: Use of Pre-Scripted Events as a Part of an Interactive Spatial Mediation Framework', TIDSE '03 Technologies for Interactive Digital Storytelling and Entertainment, Editors: S. Goebel, N Braun ve diğerleri, Farunhofer IRB Verlag, Germany, Darmstadt, pp. 296-310.

Saakes, D. and Stappers, P. J. (2002) “Designing Architectural Walkthroughs: From Simulations to Presentations by Visualising Narrative Transitions", International Journal of Design Computing Volume-4, http://pandora.nla.gov.au/ pan/10119/20030621-0000/www.arch.usyd.edu.au/kcdc/ journal/vol4/index.html [Erişim Tarihi: 8.12.2018].

[URL-1] https://arch.metu.edu.tr/system/files/About/odtu_ ankarayerleskesi_mekansalstrateji_ve_tasarim_kilavuzu_28haz2016.pdf. 